\title{
THE STUDY ON CORRELATION OF DERMATOGLYPHICS AND SCHIZOPHRENIA
}

P S Bhusaraddi ${ }^{1}$, Pavan P Havaldar*1, Pramod Rangasubhe ${ }^{1}$, Shaik Hussain Saheb ${ }^{2}$.

${ }^{1}$ Department of Anatomy, Gadag Institute of Medical Sciences, Gadag, Karnataka, India.

${ }^{2}$ Department of Anatomy, JJM Medical College, Davanagere, Karnataka, India.

\section{ABSTRACT}

Background: Dermatoglyphics is the study of quantitative and qualitative patterns of ridges in palms and soles. It is being investigated in diseases having genetic basis. The recent evidence from adoption studies has provided a basis for the genetic contributions in schizophrenia. The present conducted to study the finger and palmar dermatoglyphic patterns in schizophrenics and to compare dermatoglyphic configurations of schizophrenics with the normal population.

Materials and Methods: The ink and pad method was followed to take finger and the palm prints. The palmar prints of 50 schizophrenic patients and 50 normal individuals of both the sexes were collected for the study.

Results: There is statistically significant decrease in frequency of arches in schizophrenics when compared to controls, whereas frequency distribution of radial loops, ulnar loops and whorls are not significant. Increase in 14 interdigital pattern is statistically significant in schizophrenics when compared to controls. There is increase in the mean values of total finger ridge count in male, female and combined series of male and female schizophrenics and decrease in absolute finger ridge count in male and combined series of male and female schizophrenics, while there is decrease in female schizophrenics, when compared to controls. Atd angle is decreased in both the hands of male schizophrenics and right hand of female schizophrenics as compared to controls, whereas it is equal in the left hand of schizophrenics and controls. There is increase in the mean ridge count in III, IV and V digits in the right hand of male schizophrenics.

Conclusion: There are significant differences in the schizophrenics in various dermatoglyphic features, when compared to controls. Hence it is possible to identify the 'at risk' population with the help of dermatoglyphics. KEY WORDS: Dermatoglyphics; Schizophrenia; atd angle; a-b ridge count, mean ridge count.

Address for Correspondence: Dr Pavan P Havaldar, Department of Anatomy, Gadag Institute of Medical Sciences, Gadag, Karnataka - 582103, India. Mobile - 9986592589

Access this Article online

Quick Response code

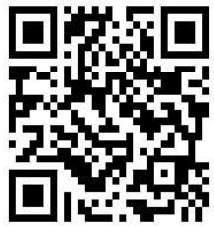

DOI: $10.16965 /$ ijar.2019.267

Journal Information

International Journal of Anatomy and Research

ICV for 2016 ISSN (E) 2321-4287 | ISSN (P) 2321-8967

90.30

https://www.ijmhr.org/ijar.htm

DOI-Prefix: https://dx.doi.org/10.16965/ijar

Article Information

Received: 04 Jul 2019

Peer Review: 04 Jul 2019

Revised: None
Accepted: 05 Aug 2019

Published (O): 05 Sep 2019

Published (P): 05 Sep 2019

\section{INTRODUCTION}

Dermatoglyphics is the science which deals with the study of dermal ridge configurations on the digits, palms and soles. The term dermatoglyphics is derived from Greek words 'Derma' meaning skin and 'Glyphae' meaning to carve. It is one of the recent and advancing branches of medical science where the dermal ridge patterns are studied and used in analysis of genetic disorders. Dermatoglyphic studies are concerned with the epidermal ridges which form systems of lines, parallel in small fields, on the surface of stratum corneum which is the outermost layer of epidermis. The pores of sweat gland ducts lie along the centres of ridges. The depressions between the ridges are known as furrows. In the underlying structures of epidermis, in particular in the basal layer of the stratum germinativum, 
glandular folds and furrow folds follow the alignment of the ridges and furrows. The characteristics of these ridges are never disturbed unless the skin is damaged to a depth of about one millimeter. Many diseases have genetic etiology. Abnormality in the genetic configurations of parents is inherited by children and reflected in the dermatoglyphic pattern. Hence dermatoglyphic study proves to be very useful, easily applicable, inexpensive, indispensable marker tool as an indicator in the diagnosis of hereditary diseases in patients. Abnormal variations in dermatoglyphic pattern are known to occur in genetic disorders like Mongolism, Turner's syndrome, Schizophrenia, Klinefelter's syndrome etc.

The study of dermtoglyphic abnormality has been employed in a number of chromosomal disorders, congenital malformations and neurological and neuropsychiatric conditions in order to gain insight into the complex interaction of environmental, developmental and genetic factors leading to disease [1].

Genetic factor is one of the important factors which influences the dermal ridge differentiation which takes place in early foetal life. The term glyphologics is a branch of genetics dealing with the skin ridge system. The scientific value of dermatoglyphics largely derives from the fact that dermal ridges appear in the third to fifth month of foetal development and the patterns then formed never change. Dermatoglyphic traits are genetically determined. Dermatoglyphic abnormalities are due to genetic or other factors that express their effect before the end of fifth month of foetal intrauterine life development. The permanency of finger patterns, the extreme variability from one individual to the other and easy analysis are some of the reasons for its wide application in a variety of conditions. The recent evidence from adoption, twin and family studies have proved a basis for genetic contributions in schizophrenia. Schizophrenia is a severe psychiatric disorder. The term schizophrenia has its origin from Greek words 'Schizen' meaning to split and 'phrein' meaning mind. Schizophrenia is hypothesized to be the result of an interaction between specific genetic factors and nonspecific insults during embryonic development[1].
Dermatoglyphic abnoramlities appear to mark these putative insults providing information about the temporal sequence of aberrant developmental events as well as organism's vulnerability to their adverse effects. Search for the etiology of schizophrenia is still continuing. Biological, psychological and social factors have been implicated but no consensus has emerged till now. One of the factors studied in this context is dermatoglyphics. A large number of dermatoglyphic studies in schizophrenia have been published. The fundamental assumption is that since many genes take part in the formation of dermatoglyphic characters, it is possible that genes which predispose to familial disease may, by pleiotrophy, also influence the ridge patterns so that particular constellations of dermatoglyphic features may be characteristics of a particular disease[2]. Hence the present study was undertaken to determine the significant dermatoglyphic patterns applicable to schizophrenia, which can serve to strengthen the diagnosis of schizophrenia.

\section{MATERIALS AND METHODS}

The palmar prints of 50 schizophrenic patients (21 males and 29 females) from Chigateri General Hospital and Bapuji Hospital, Davangere were taken. The palmar prints of 50 schizophrenic patients of both the sexes (21 males and 29 females) clinically diagnosed under DSM-IVT R criteria aged $18-60$ years were collected for the study. The palmar prints of 50 normal individuals of both the sexes ( 21 males and 29 females), aged between $18-60$ years who were medically and psychologically healthy were collected to serve as control against schizophrenic patients.

The print of dermatoglypics were taken as follows. The glass slab was kept on the table. A small amount of duplicating ink was spread over it by means of rubber roller to obtain a thin uniform film of ink on the glass. The fingers of the individual's right hand were inked over the glass by firm pressure, starting from the thumb. The crystal bond paper kept over the wooden table was used for recording the finger print pattern. The finger was first placed edge down on the ink film and then rolled until the opposite margin was in contact. For ease, the thumb was 
placed downward and rolled towards the body and the other fingers placed radial edge downward and rolled away from the body. The same procedure was followed for recording the finger prints of the left hand. Thus rolled prints of all the fingers were obtained and recorded. The palm of the individual's right and left hand was inked with the help of rubber roller. Palm was kept on the inking slab and firm pressure was applied over the zone of flexion creases at the wrist, the ulnar margin, flexor creases where the fingers join the palm and central hollow of the palm. Then the palm was kept on the crystal bond paper and firm pressure applied over the central region of the hand, over the knuckles, to ensure printing of the hollow of the palm and the distal border. Soon after the print was taken, it was examined for details and clarity in different fingers and palmar areas. The materials were used, Kores quick drying duplicating ink, Rubber roller, Inking slab - thick glass sheet fixed over wooden support, Cotton puff and spirit, Scale, Crystal bond paper, Pencil, Protractor, Magnifying lens, Soap and towel, Ink pad (Fig. 1).

Fig. 1: Materials used in study.

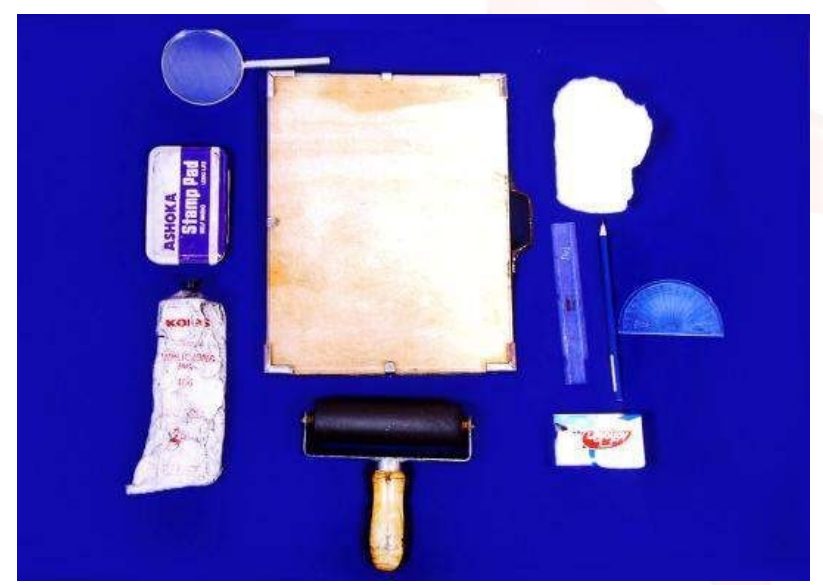

Statistical analysis: Descriptive statistics are presented as mean and standard deviation for continuous data and number and percentage for categorical data. $\mathrm{Z}$ test/ unpaired ' $\mathrm{t}$ ' test was used for comparing the means of two groups (Cases Vs Control). Categorical data was analysed by Chi-square test and Fisher's Enact test wherever necessary. $p$-value of 0.05 or less was set for statistical significance.

\section{RESULTS AND DISCUSSION}

The scientific value of dermatoglyphics largely derives from the fact that dermal ridges appear in the third to fifth month of foetal development and the patterns once formed never change. Dermatoglyphic traits are genetically determined. Dermatoglyphic abnormalities are due to genetic or other factors that express their effect before the end of fifth month of foetal development. The recent evidence from adoption, twin and family studies have proved as a basis for genetic contributions in schizophrenia, hence dermatoglyphic variation is an essential investigation in its early diagnosis.

The present study consists of 50 schizophrenic patients (21 males and 29females) clinically diagnosed under DSM-IVT R criteria aged 18-60 years and 50 healthy controls ( 21 males and 29 females) aged $18-60$ years. The prints were obtained by the ink method and analysed to find variations in dermatoglyphic features among patients and controls. The following parameters were observed in the present study. Qualitative analysis of finger tip patterns, Quantitative analysis of finger prints, i.e. Total finger ridge count and Absolute finger ridge count, Patterns in interdigital areas and hypothenar areas, Mean ridge count, atd angle, $a-b$ ridge count

In the present study of 50 schizophrenics and 50 controls, the frequency of distribution of finger tip patterns in both hands are : Arches; Schizophrenics $-4.6 \%$, controls $-10 \%$; Radial loops: schizophrenics - $1.8 \%$ controls - 3.6\%; Ulnar loops: schizophrenics - 59.6\%, controls $55.2 \%$; Whorls : schizophrenics $-34 \%$, controls $-31.2 \%$. Schizophrenics had significantly lower arches than controls. Whorl pattern was found to be significantly increased in the right hand of schizophrenics when compared to controls.

Srinivas Murthy $\mathrm{R}$ [3] observed Arches: schizophrenics - $4.33 \%$, controls - $2.25 \%$; Loops: schizophrenics $-54.33 \%$, controls $-50.58 \%$; Whorls : schizophrenics $-41.54 \%$, controls $47.17 \%$ in a study of 120 schizophrenics and 120 controls. Male schizophrenics had an increase in the arch pattern frequency and decrease in whorl frequency. Vishwanathan CP et al [4]observed Arches : schizophrenics $-4.61 \%$, controls - 4.48\%; Radial loops : schizophrenics - 1.9\%, controls - 2\%; Ulnar loops : schizophrenics $53.9 \%$, controls $-56.5 \%$; Whorls : schizophrenics - $39.6 \%$, controls $-37 \%$ in a study of 100 schizophrenics and 160 controls. Finger print 
patterns did not show statistically significant difference. Das Gupta J[5] observed higher percentage of ulnar loop and whorl in both the sexes. Jhingan HP, Munjal GC [6] observed fewer arches and whorl patterns and more loops on the fingers.

The observations of present study correlate with earlier observations of Das Gupta J. and Jhingan $[5,6]$. In the present study of 50 schizophrenics and 50 controls, there is an increase in the mean values of Total finger ridge count in male (143.71), female (135.69) and combined series of male and female schizophrenics (139.06), when compared to controls (male - 123.43, female - 133.86, combined - 129.48) which is statistically not significant. There is an increase in the Absolute finger ridge count in male (186.24) and combined series of male and female (179.84) schizophrenic patients, while there is decrease in the Absolute finger ridge count in female (175.20) schizophrenics patients as compared to controls (males - 144.90, females -177.83, combined -166.00), which is statistically not significant. In the observations made by Srinivas Murthy R[3], Wig NN14 in 120 schizophrenic patients and 120 controls, there was decrease in the Total finger ridge count in schizophrenics (141.38) as compared to those of controls (148.04) which is statistically not significant. In the study by Jhingan HP[6] in 50 schizophrenics and 50 controls, there was increase in the Total finger ridge count in female schizophrenics as compared to controls. The observations of the present study coincide with this.

In the present study of 50 schizophrenics and 50 controls, it has been observed that there is increase in 14 pattern (42\%) which is statistically significant in schizophrenics when compared to controls (29\%), while Thenar/I1 , 12,13 and Hypothenar area did not show any statistical significance. Thenar/I1: schizophrenics - 2\%, controls $-0 ; 12$ : schizophrenics - 4\%, controls - 7\%; 13 : schizophrenics - $22 \%$, controls - $27 \%$; Hypothenar area : schizophrenics $-13 \%$, controls $-10 \%$.

Das Gupta J[5] observed that there were more patterns in area 14 and a gradual decrease of the same in the 13 and 12 . The observations in the present study coincide with this.
Vishwanathan CP et al[4] observed an increase in 13 pattern which was significant in schizophrenic males (50.59) when compared to normal males (38.67). Jhinga n HP[5] observed fewer patterns in 13 palmar area. Frequency of patterns in the Thenar/11 palmar area in schizophrenics was 8 as compared to 13 in controls. In 12 palmar area, patients had a total of 9 patterns whereas controls had 8 . Number of patterns in 14 palmar area of patients was 61 as compared to 55 of controls.

In the present study of 50 schizophrenics and 50 controls, atd angle is decreased in the schizophrenic patients (right - 39.98, left - 40.4) when compared to controls (right -41.02 , left -41.06 ) which is not statistically significant. In male schizophrenic, atd angle is decreased (right 40.29 , left -39.38 ) when compared to controls (right -40.67 , left -40.95 ). In right hand of female schizophrenic patients, atd angle is decreased when compared to controls. (Schizophrenics - 37.76, Controls - 41.28) whereas atd angle is equal in left hand of schizophrenics and controls (schizophrenics 41.14 , controls -41.14 ). These values were not statistically significant.

In a study of 85 schizophrenics and 75 controls, Vishwanatham CP et al[4] observed increase in the mean values of atd angle in schizophrenic males (mean $=77.64)$ when compared to control (mean $=76.51$ ) which was statistically not significant. In 120 schizophrenics and 120 controls, Srinivas Murthy R[3] observed an increase in the mean values of atd angle (mean $=78.25$ ) in schizophrenic when compared to control males (mean $=77.42$ ) which was statistically not significant. In 50 schizophrenics and 50 controls, Jhingan HP, Munjal GC18 observed decrease in the atd angle in schizophrenic males (mean $=74.48$ ) when compared to normal males (mean $=82.55$ ) which was statistically significant.

In the present study of 50 schizophrenics and 50 controls, mean a-b ridge count of left hand of schizophrenics (mean $=35.14$ ) is decreased when compared to controls (mean $=35.48$ ). Mean $a-b$ ridge count of right hand of schizophrenics (mean $=34.62$ ) is increased when compared to controls (mean $=34.12$ ). These values are statistically not significant. In 
the present study, there is significant increase in the mean ridge count in III, IV and V digits in the right hand of male schizophrenics than controls. There is also statistically significant increase in the mean ridge count in the III digit of right hand of combined series of male and female schizophrenics than controls. There is also significant increase in the mean ridge count in the III digit of left hand of male and combined male and female schizophrenics than controls.

\section{CONCLUSION}

The number of Arches is considerably decreased in schizophrenics. The number of Whorls is increased in the right hand of schizophrenics. Patterns in interdigital area 14 is increased in schizophrenics. There is increase in the mean ridge count in III, IV and V digits of the right hand of male schizophrenics. There is increase in the mean ridge count in the III digit of right hand of combined male and female schizophrenics. There is increase in the mean ridge count in the III digit of the left hand of male and combined male and female schizophrenics.

\section{Conflicts of Interests: None}

\section{REFERENCES}

[1]. Singh IP, Bhasin MK. A manual of biological anthropology. Delhi : Kamla Raj Enterprises; 2004 .p.31826.

[2]. Bannister LH, Berry MM, Couins P, Dyson M, et al. Gray's anatomy - The anatomical basis of medicine and surgery. 38th ed. Edinburgh London: Churchill Livingstone; 2000 .p.380.

[3]. Srinivas Murthy R, Wig NN. Dermatoglyphic study of male schizophrenics. Indian J Psychiatry 1977;19(3):48-51.

[4]. Vishwanathan CP, Vijayalakshmi G, Subramanyam TS. Deramtoglyphics in schizophrenia South India males. J Anat Soc India 1980;29(1):19-23.

[5]. Dasgupta J, Dasgupta D, Balasubrahmanyan M. Dermatoglyphics in diagnosis of schizophrenia. Indian J Psychiat 1973;15:104-22.

[6]. Jhingan HP, Munjal GC. Dermatoglyphics in female catatonic schizophrenics. Indian J Psychiat 1989;31(4):329-332.

\section{How to cite this article:}

P S Bhusaraddi, Pavan P Havaldar, Pramod Rangasubhe, Shaik Hussain Saheb. THE STUDY ON CORRELATION OF DERMATOGLYPHICS AND SCHIZOPHRENIA. Int J Anat Res 2019;7(3.3):6961-6965. DOI: 10.16965/ijar.2019.267 